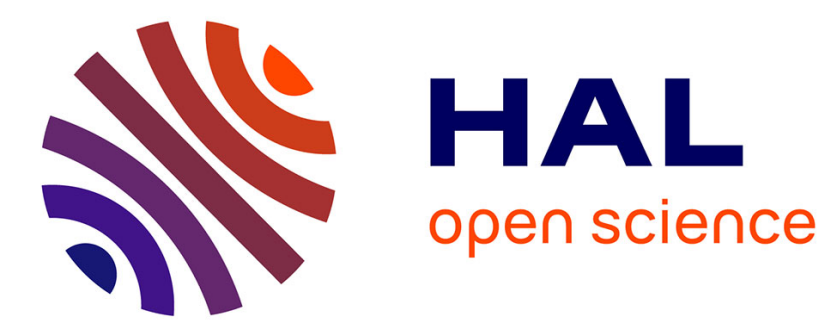

\title{
Why does the lumen maintenance of sodiumscandium metal halide lamps improve by VHF operation?
}

\author{
W van Erk, G M J F Luijks, W Hitchcock
}

\section{To cite this version:}

W van Erk, G M J F Luijks, W Hitchcock. Why does the lumen maintenance of sodiumscandium metal halide lamps improve by VHF operation?. Journal of Physics D: Applied Physics, 2011, 44 (22), pp.224001. 10.1088/0022-3727/44/22/224001 . hal-00620588

\section{HAL Id: hal-00620588 \\ https://hal.science/hal-00620588}

Submitted on 8 Sep 2011

HAL is a multi-disciplinary open access archive for the deposit and dissemination of scientific research documents, whether they are published or not. The documents may come from teaching and research institutions in France or abroad, or from public or private research centers.
L'archive ouverte pluridisciplinaire HAL, est destinée au dépôt et à la diffusion de documents scientifiques de niveau recherche, publiés ou non, émanant des établissements d'enseignement et de recherche français ou étrangers, des laboratoires publics ou privés. 


\title{
Why does the lumen maintenance of sodium-scandium metal halide lamps improve by VHF operation?
}

\author{
W. van Erk ${ }^{1}$, G.M.J.F. Luijks ${ }^{2}$, W. Hitchcock ${ }^{3}$ \\ ${ }^{1}$ Retired employee Philips Lighting, Sondervick 47, 5505 NB Veldhoven, The Netherlands \\ ${ }^{2}$ Advanced Development Lighting, Philips Lighting, P.O. Box 80020, 5600 JM Eindhoven, The Netherlands, \\ Gerard.luijks@philips.com \\ ${ }^{3}$ Philips Lighting Company, 7265 Route 54, Bath, NY 14810, USA.
}

\begin{abstract}
Lifetime experiments show that sodium scandium metal halide lamps perform better on VHF (Very High Frequency) drivers than on LF (Low Frequency) CWA ballasts. The question why, will be addressed with focus on arc tube aspects. It is argued that at high frequency operation sodium loss is less, and that the absence of thermal fluctuations in the electrode tip causes less damage and cracking to this part of the electrode. Sudden $1 \mathrm{~m} / \mathrm{W}$ drops, observed with CWA-operated lamps, most probably occur when the arc attaches on such a corroded and cracked surface.

Thorium is effective as an emitter both in the CWA and the VHF operation mode, despite the absence of cataphoretic transport to the cathode in the VHF case.
\end{abstract}

\section{Introduction}

The sodium scandium metal halide lamps discussed here are designed to be operated on conventional magnetic Constant Wattage Autotransformer (CWA) systems . Tests reported in literature as well as own investigations have shown that these lamps perform very well on electronic Very High Frequency (VHF) systems [1,2]. Especially the lumen per watt (LPW) maintenance on VHF is better than on the conventional CWA system. Despite of this advantage, in the majority of lighting systems for these lamps still the conventional gear is used because of their long lifetime and also the higher price of electronic drivers.

In the lumen per watt maintenance of metal halide lamps several effects play a role like spectral changes and wall blackening due to the deposition of tungsten. Lamouri et al.[1] report that $150 \mathrm{~W}$ lamps burned on magnetic ballasts revealed more blackening of the arc tube than on electronic drivers. A test with fast cycling of the lamps ( 2 minutes ON and 28 minutes OFF) showed that the lumen depreciation is not related to starting but must occur during normal operation [1]. Furthermore, chemical analysis of the lamp filling after $9000 \mathrm{hrs}$ of operation showed no significant difference between lamps operated on magnetic ballasts versus electronic drivers [1]. This excludes spectral differences from being the major cause of difference in light output. The authors conclude that the current crest factor and the operating frequency are not responsible for the improved lumen maintenance on electronic drivers. They suggest that the cathode peak temperature is the dominant factor. With respect to differences in voltage rise the reported results are not unequivocal. A test with horizontal burning $350 \mathrm{~W}$ lamps resulted in less voltage rise, and so less sodium loss, for lamps operated on VHF [2]. For $150 \mathrm{~W}$ lamps burning in vertical orientation for $9000 \mathrm{hrs}$ the voltage rise was similar regardless of the ballast type [1].

This paper will address the question why these lamps perform better on VHF and will focus on the lamp side of the system, on physical, chemical and mechanical effects of the very high frequency operation mode.

\section{Observations and experimental results}

In all tests described, the lamps burned vertically with base up and the lamps contained an excess scandium metal, a small amount of thorium iodide in the salt and tungsten electrodes containing $2 \%$ thorium oxide. A first test with 400W sodium scandium lamps (Philips type MS400/BU/PS, ten lamps 
per set) resulted in a LPW maintenance of $83 \%$ at 10,000 hours with a standard deviation of $4 \%$ on VHF drivers (type Advance Dynavision ${ }^{\mathrm{TM}}$ ), much better than the controls on CWA ballasts: $51 \%$ maintenance with standard deviation of $6 \%$ (figure 1).

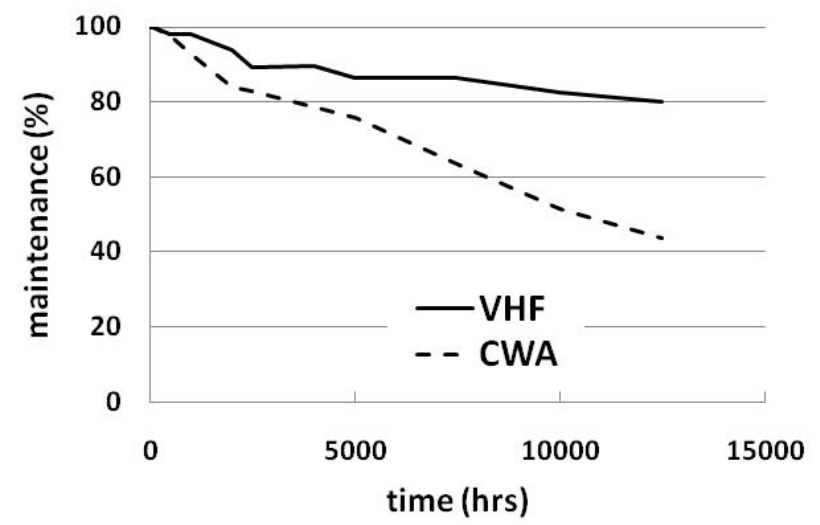

Figure 1 Average lumen maintenance of MS 400/BU/PS sodium scandium lamps burning on VHF (100 kHz) or CWA $(60 \mathrm{~Hz})$ systems.

Striking is also the difference in lamp voltage rise at 10,000 hours as is shown in figure 2: $12 \mathrm{~V}$ on VHF and $22 \mathrm{~V}$ on CWA.

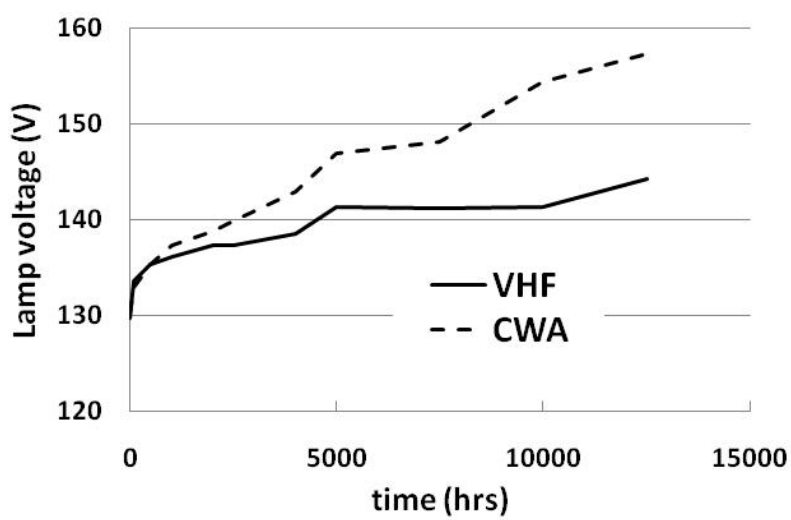

Figure 2 Average RMS lamp voltage of 10 MS 400/BU/PS sodium scandium lamps operated on either VHF or CWA systems

The salt compositions of one VHF lamp and two CWA lamps were analyzed at 10,000 and 12,500 hours, respectively (table 1). The CWA lamps had lost more than $10 \%$ of their sodium, whereas for the VHF lamp the loss was not measurable. This is corroborated by the $\mathrm{Na} / \mathrm{Sc}$ ratio: sodium loss will lead to a lower $\mathrm{Na} / \mathrm{Sc}$ ratio and indeed the $\mathrm{Na} / \mathrm{Sc}$ mole-ratio is lower for the two CWA lamps: 19/1 and $22 / 1$ versus $28 / 1$ for the VHF lamp [4].

\begin{tabular}{ccccc}
\hline Lamp nr & Life $(\mathrm{h})$ & Thorium $(\mu \mathrm{g})$ & $\mathrm{Na} / \mathrm{Na}$ dosed & $\mathrm{Na} / \mathrm{Sc}$ ratio \\
\hline CWA 1 & 110 & 323 & $100 \%$ & 33 \\
CWA 2 & 12,500 & 1250 & $85 \%$ & 19 \\
CWA 3 & 12,500 & 939 & $86 \%$ & 22 \\
VHF 2 & 10,000 & 793 & $103 \%$ & 28 \\
\hline
\end{tabular}

Table 1. Results of the chemical analysis of the salt in some of the MS 400/BU/PS lamps

Lumen maintenance of these lamps is strongly correlated with wall blackening, i.e. deposition of tungsten on the arc tube wall, as can be seen in figure 3.a. 


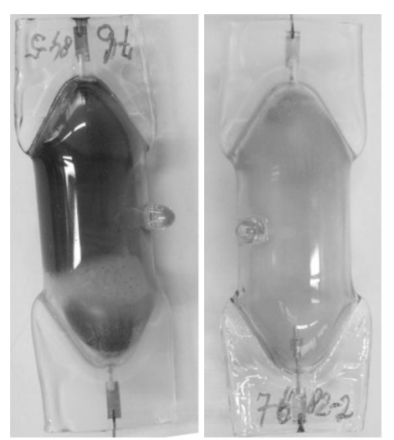

Figure 3.a Picture of one MS 400/BU/PS arc tube aged on CWA (12,500 hours, left hand picture) and one on $\operatorname{VHF}(10,000$ hours, right hand picture).
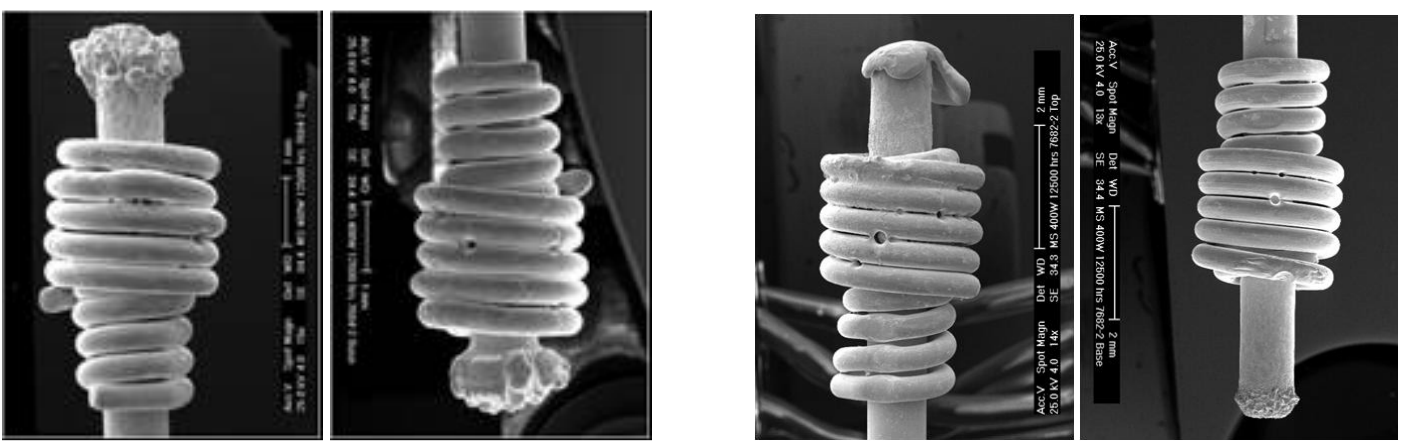

Fig 3.b. Scanning Electron Microscope pictures of the electrodes of a MS 400/BU/PS arc tube aged on CWA (12,500 hours, left hand pictures) and one on VHF (10,000 hours, right hand pictures) The electrodes are shown in their burning position.

Deposition of tungsten on the arc tube wall strongly depends on electrode performance since in this kind of lamps a regenerative tungsten cycle is not possible due to the absence of oxygen to form tungsten oxy-iodides [3]. Some representative electrode pictures are shown in figure 3.b. Out of a second test of ten MS400/BU/PS M155 lamps that had reached 4000 hours, for three lamps the amount of tungsten on the arc tube wall was measured using wet chemical analysis, and the electrodes were examined using a SEM (Scanning Electron Microscope). Striking is the very large difference in the amount of tungsten that has reached the arc tube wall: $1.4(0.3) \mathrm{mg}$ W for CWA and $0.09(0.02)$ $\mathrm{mg} \mathrm{W}$ for VHF (figure 4).

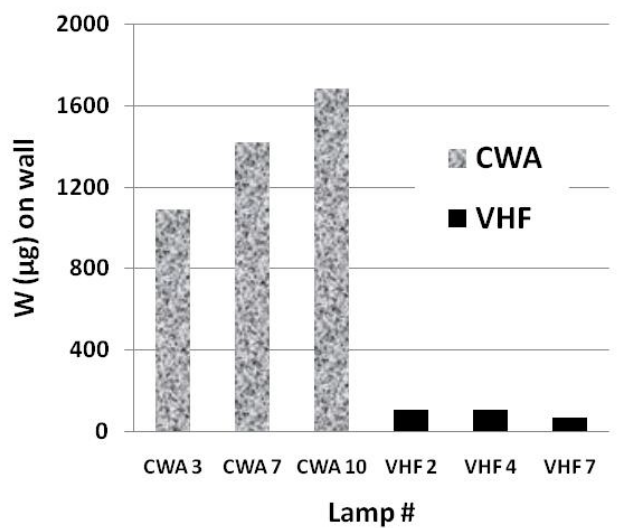

Figure 4. The amount of tungsten $(\mu \mathrm{g})$ found on the arc tube wall after 4000 hours of operation on either a CWA or a VHF system. 
In figure 5 examples of electrode tip appearances after 4000 hours are shown.. The lower electrodes have a rather smooth surface with the typical "mushroom" shape. In the CWA lamps cracks are found in the tip surface, whereas the lower electrodes of the VHF lamps hardly have any cracks.

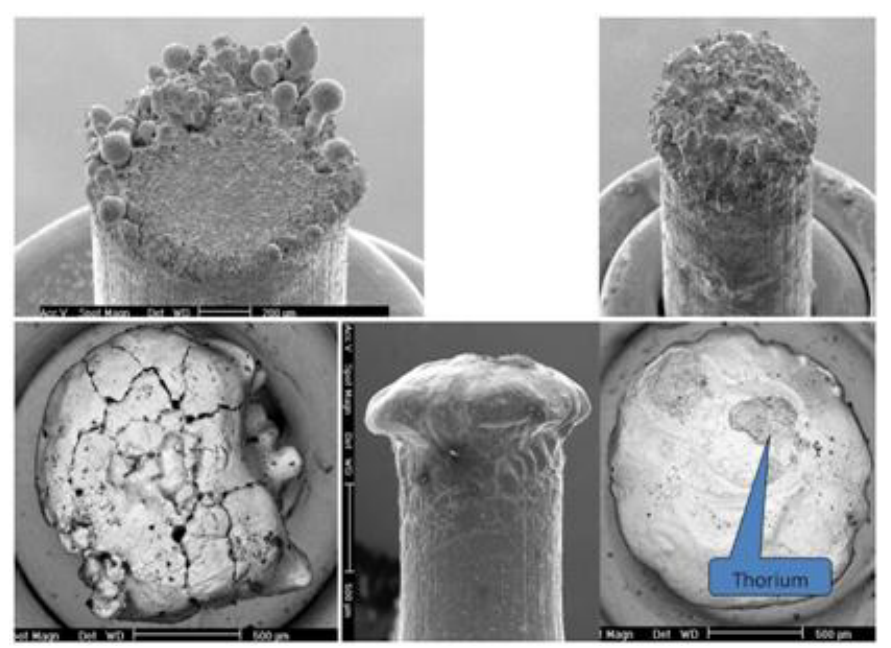

Figure 5. Electrode surfaces after 4000 hours burning vertically base up. Upper pictures are from the upper electrodes and the lower pictures from the lower electrodes. The electrodes on the left have burned on CWA ballasts and those on the right on VHF drivers. On the lower electrode of one of the three examined VHF lamps a macroscopic thorium deposit was still present. Below in the middle is a side view of the lower VHF electrode

On one of the VHF electrode tips a thorium deposit was still present [4]. For the upper electrodes holds that on the CWA electrode tips protrusions are seen whereas with VHF the surfaces are more smooth. By grinding and polishing a cross section was made through the electrodes parallel to the electrode axis. With laser-ablation combined with ICP-MS (Inductively coupled plasma and mass spectrometry) the thorium content in the electrodes was measured as a function of the distance to the tip. In the lower electrodes the first $0.5 \mathrm{~mm}$ appeared to be completely depleted of thorium. In the upper electrodes the depletion after $4000 \mathrm{hrs}$ is much less. There a concentration profile was found over 0.1 to $0.4 \mathrm{~mm}$ from the tip. During prolonged burning the depleted area increases, for both electrodes.

In an earlier experiment in which the role of thorium was examined it was found that the presence of thorium in the arc tube is essential to obtain a good maintenance: At 1000 hours the average maintenance of the set without any thorium was about $70 \%$ whereas, with thorium either in the salt or in the electrodes or in both the maintenance was above $90 \%$.

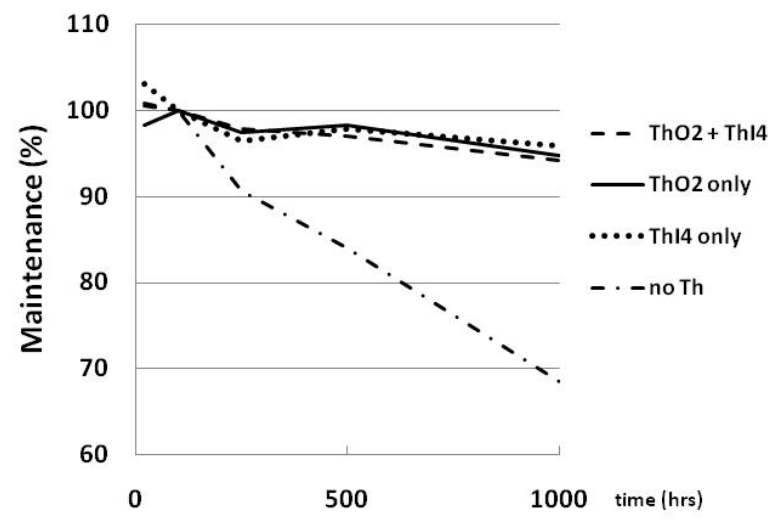

Figure 6. Lumen maintenance for the first 1000 hours of operation on CWA of lamps with thoriated electrodes $\left(\mathrm{ThO}_{2}\right)$ and/or thorium iodide $\left(\mathrm{ThI}_{4}\right)$ in the salt and lamps without any thorium in the arc tube . 
In principle scandium can be a good gaseous emitter but apparently here its pressure is not high enough to yield sufficient coverage and thorium is necessary to fulfill the emitter function properly [5].

To find out whether CWA or VHF operation results in a different temperature of the electrode tip, the time-averaged electrode temperature of the upper electrode of a MS 400/BU/PS lamp has been measured (figure 7).
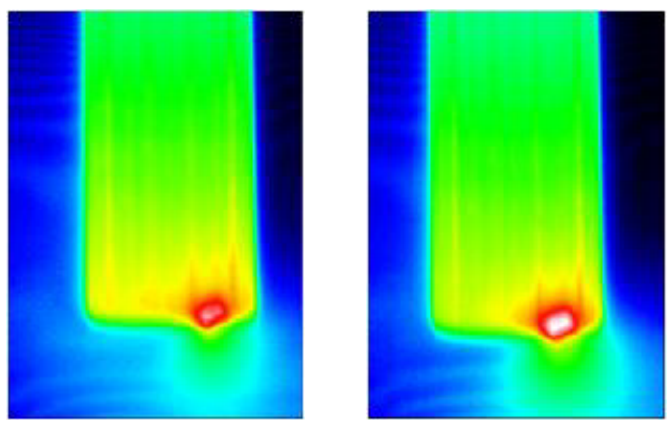

Figure 7. Time-averaged thermal images of the upper electrode of a MS 400/BU/PS lamp at 100 hours. Left hand image is on CWA and the right hand image the same lamp but now on VHF

The average tip temperatures obtained by extrapolation of the measured temperature profiles to the tip position are $2502 \mathrm{~K}$ for CWA operation and $2467 \mathrm{~K}$ for VHF operation, respectively. From these measurements a work function of $3.6 \mathrm{eV}$ can be derived, both for CWA and VHF operation. This low value of the work function is ascribed to the presence of thorium on the electrode surface. For comparison, the work function without emitter is $4.5 \mathrm{eV}$ (pure tungsten), which leads to a much higher tip temperature $(3020 \mathrm{~K}$, calculated) under the present electrode and lamp conditions. Time resolved observations showed that the arc attachment changes periodically from diffuse in the anode phase to constricted in the cathode phase for CWA operation. For VHF operation the arc attachment is constricted both in the anode and cathode phase (see also fig. 9).

\section{Discussion}

In the lumen per watt maintenance of metal halide lamps several effects play a role like spectral changes and wall blackening due to the deposition of tungsten. Of these two effects, wall blackening is the most dominant one for the sodium scandium lamps discussed here (see fig 3.a).

In these lamps there is no regenerative tungsten cycle due to the reactivity of scandium towards oxygen [3]. Therefore, once tungsten coming from the electrodes has reached the arc tube wall and has deposited there it will stay there. This deposition process can be described using crystal growth theory and in this description the super-saturation is an important parameter [3]. A high super-saturation leads to a high number density of small tungsten crystals and a low super-saturation to a low number density of large crystals. The latter situation with a low number density of large particles is more favourable because it results in better light transmission of the arc tube wall. In the sodium scandium lamps the wall temperature is low, around $1000 \mathrm{~K}$, and in the beginning of lamp life the "free iodine" pressure, $\mathrm{HgI}_{2}$, is very low, due to the presence of an excess of scandium metal. These two effects enhance the super-saturation. The third parameter determining the super-saturation is the electrode tip temperature. A low tip temperature diminishes the super-saturation. Therefore, in order to still get reasonable lumen maintenance performance the maximum tip temperature of the electrodes should be low. This is indeed the case in the lamps discussed here. The combination of a well designed electrode and thorium as an emitter results in a for metal halide lamps relatively low electrode temperature (figure 7). Besides the super-saturation, also the rate of transport of tungsten to the wall is an important parameter. This depends on the sum tungsten pressure at the electrode tip. Here too, the tip temperature is an important parameter and furthermore the iodine pressure plays an important role because tungsten is transported not only as tungsten atoms but also as tungsten iodides. In conclusion this means that the design and functioning of the electrodes is of crucial importance for the lumen maintenance performance 
Emitter: First the situation early in lamp life will be discussed. At 100 hours the average tip temperature of the upper electrode is about the same and low for both CWA and VHF (figure 7). In figure 8 the result of modeling of the phase-resolved tip temperature is shown. The current at VHF operation (3.1A, RMS) is somewhat lower than at CWA operation (3.3A, RMS) due to the difference in power factor. In the calculation this leads to a slightly lower average temperature in case of VHF. Hereby we assumed that in both cases the work function is the same $(3.6 \mathrm{eV})$, as a result of the emitter effect of thorium being present on the tip surface, as mentioned earlier. Would this not be the case then a calculation shows that with a work function of $4.5 \mathrm{eV}$ the tip temperature is expected to be more than $3000 \mathrm{~K}$. This is certainly not observed. The calculations in figure 8 also show that under the present conditions the heating of the electrode occurs predominantly in the anode phase.

There is no macroscopic thorium deposit on the upper electrode like there is on the lower one. The supply of emitter to the electrode surface is via the gas phase (the gas-phase emitter mechanism $[5,6]$ ) and by diffusion of thorium from the inside of the electrode to the surface. Part of the emitter flux from the gas phase to the cathode surface is due to cataphoresis of the emitter ions and part is normal adsorption (see figure 9). In the anode phase the cataphoretic flux of emitter ions is away from the electrode surface. With $60 \mathrm{~Hz}$ operation (CWA) this leads to a removal of the emitter from the surface (figure 9, left-hand drawing). So with CWA operation there is a cyclic process of covering with emitter in the cathode phase and removal in the anode phase. And there is the flux from the interior to the surface, but this flux will diminish during time as the region near the electrode tip gets more and more depleted.

At high frequency operation the cataphoretic flux will be almost zero because the emitter ions cannot follow the fast changes of the electric field. So with VHF there is only the normal adsorption, but of thorium it is known that it adsorbs very strongly on a tungsten surface. And at 100 hours there is still the supply of thorium from the inside to the surface. Our results show that this flux out of the electrodes combined with the flux of neutral thorium emitter atoms from the gas phase is sufficient to produce the thorium monolayer or part of a monolayer necessary for the lowering of the work function and thus of the electrode temperature. . With VHF, the absence of the cataphoretic flux away from the surface then leads to the conclusion that the emitter layer will be present in the anode phase of VHF, too. This means that with VHF the emitter thorium will be present in both the cathode and anode phase.

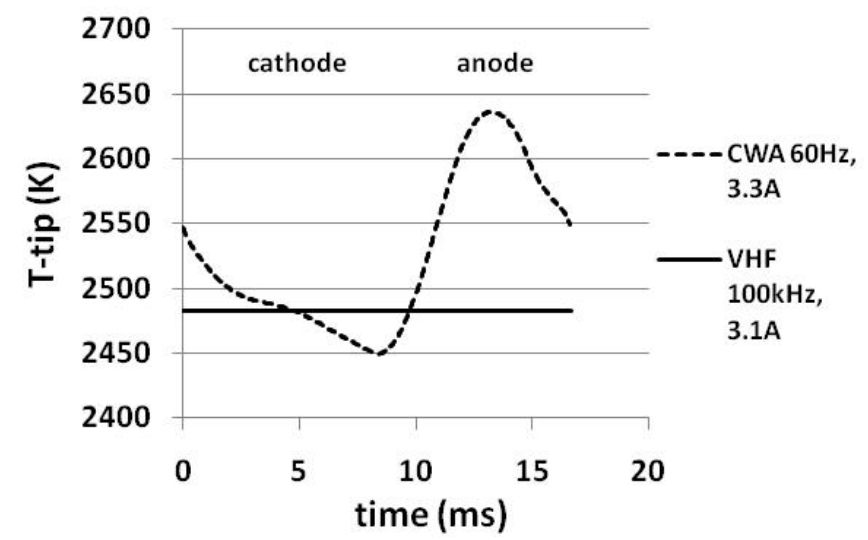

Figure 8. Calculated temperature fluctuations of the electrode tip as a function of time, both for $60 \mathrm{~Hz} C W A$ operation at $3.3 \mathrm{~A}$ RMS current and $100 \mathrm{kHz}$ VHF operation at $3.1 \mathrm{~A}$ RMS current. In both cases diffuse attachment is assumed and the work function is $3.6 \mathrm{eV}$. 

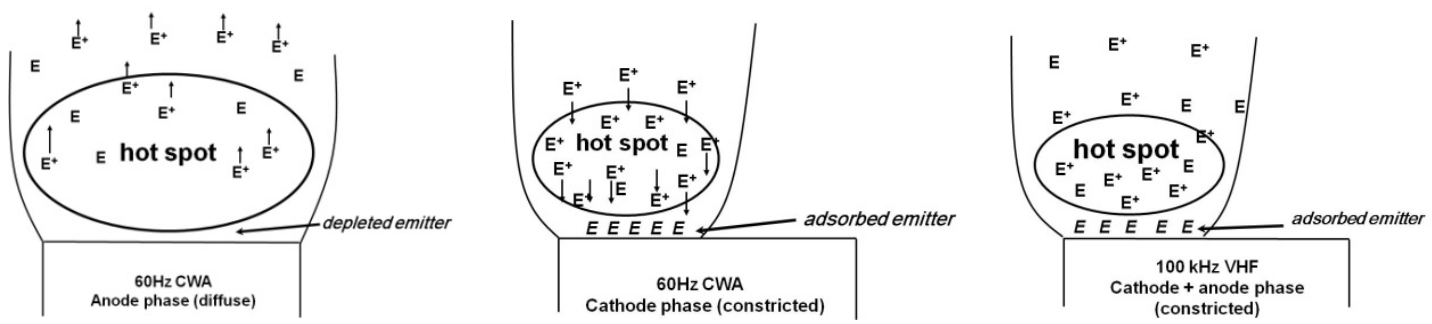

Figure 9. Schematic representation of the flux of emitter $(E)$ ions and atoms in case of CWA and VHF operation.

At the lower electrode the situation is different. During the first period of burning silicon, formed by the reaction of scandium metal with quartz glass, and scandium itself are transported mainly to the lower electrode. Due to the convection flow in the arc, material coming from the region near the salt pool will first reach the lower electrode and in the second stage the upper electrode. However, due to additive de-mixing the concentrations of the additives will be reduced when the flow reaches the upper electrode. This means that the lower electrode is much more affected by the chemistry than the upper one. At the lower electrode the silicon will dissolve in the tungsten of the hot part of the electrode rod and scandium can penetrate via pores and grain boundaries. They will reduce the thorium oxide present there and the thorium metal that is formed will travel outwards. The temporarily high silicon content of the tip can lead to local and temporarily melting of the tip resulting in the typical "mushroom" shape and a smooth surface (fig. 5 lower picture). Due to the limited amount of iodine available not all the thorium metal can form thorium iodide and this explains why there is often a macroscopic thorium deposit on the electrode tip, a liquid film or pool. So then the emitter is present in both anode and cathode phase in the VHF situation as well as in the CWA situation. During prolonged burning this deposit will disappear when the iodine pressure increases due to sodium loss. The thorium will form thorium iodide and the thorium iodide pressure in the arc tube will increase $[2,4]$. When the macroscopic thorium deposit is gone the supply of emitter to the electrode surface is only via the gas phase, because the upper part of the electrode rod is depleted of thorium. But even then, during prolonged burning on VHF, the lumen per watt maintenance does not fall back indicating that the gas-phase emitter mechanism yields an emitter coverage that is sufficient to keep the electrode tip temperature low.

The conclusion so far is that at VHF operation the electrodes perform equally well or slightly better than at CWA operation. But it does not explain yet why the tungsten removal rate is very low compared to CWA (figure 4). As the iodine pressure is an important parameter in the transport rate, sodium loss will be discussed now.

Sodium loss: The mechanism of sodium loss has been described in [4]. In the arc tube, sodium is present as sodium iodide, NaI. Sodium can escape through the quartz glass wall and iodine stays behind in the arc tube. So loss of sodium out off the arc tube leads to an increase of the amount of iodine available in the lamp. Voltage rise is one of the indicators of sodium loss. The results presented in figure 2 and table 1indicate that the rate of sodium loss is much lower on VHF than on CWA. Furthermore, the finding that after 4000 hours thorium was still present on one of the VHF electrodes is also an indication for the lower sodium loss rate at VHF operation (figure 5). Photoemission of electrons by the metal frame in the outer bulb becomes the dominant mechanism once enough sodium has escaped from the arc tube to lower the work function of these metal parts [4]. In the half-cycle that the frame has a negative charge, electrons emitted by the frame will travel to the discharge tube and can interact with the sodium ions in the quartz glass. Sodium atoms then escape from the quartz into the outer bulb. Calculations show that at very high frequencies, $100 \mathrm{kHz}$ in the present case, the direction of the field switches so fast that electrons, emitted by the field wire do not have enough time to travel through the nitrogen filled outer bulb to the arc tube surface [4]. So at VHF operation the flux of electrons to the arc tube surface will be less and this will reduce sodium loss. A consequence of this will be that the increase of the so called "free iodine" pressure $\left(\mathrm{HgI}_{2}\right)$ will be less in case of VHF compared to CWA. As tungsten is transported away from the electrodes in the form of tungsten 
iodides, a smaller increase of the iodine pressure on VHF will lead to a lower transport rate of tungsten from the electrodes to the arc tube wall (figure 10).

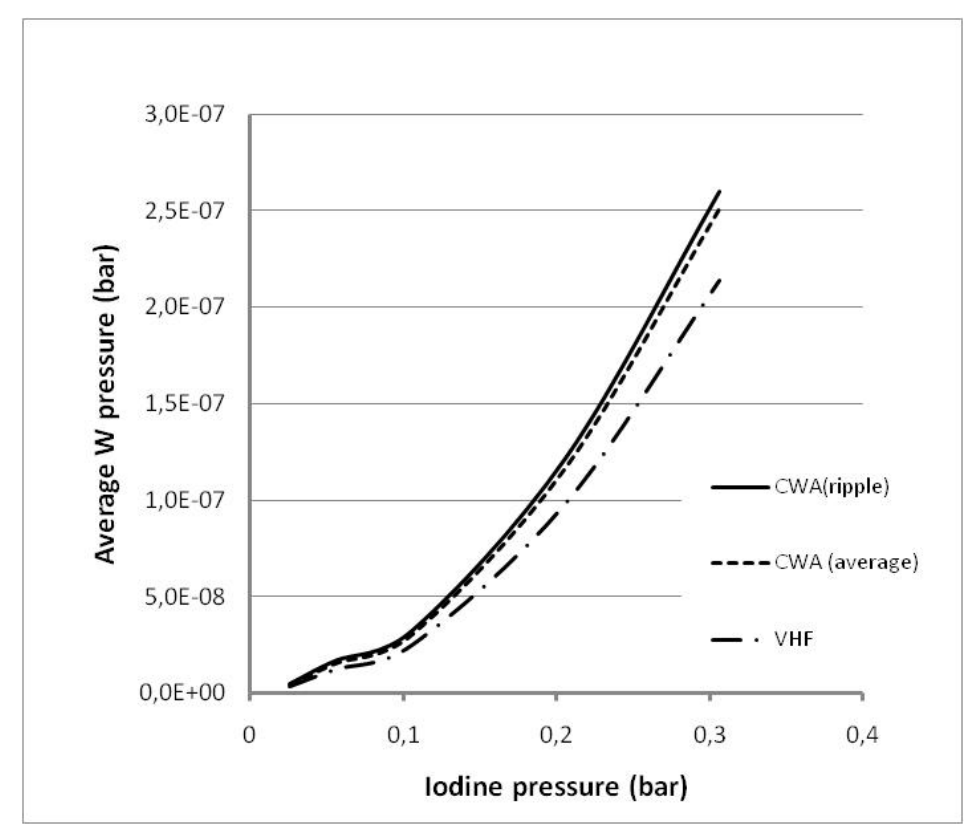

Figure 10. Calculated average sum tungsten pressures as a function of the total iodine pressure in the arc. For the average electrode tip temperatures the measured values of $2467 \mathrm{~K}$ and $2502 \mathrm{~K}$ for VHF and CWA operation, respectively, have been used. In the "CWA ripple" calculation the periodic temperature fluctuation from figure 8 was used as input for the sum tungsten calculation.

The results of the calculations of the sum tungsten pressure show that with $60 \mathrm{~Hz}$ the periodic temperature fluctuation only gives a small increase of sum tungsten when compared with the value obtained with the average temperature. The effect of the slightly lower tip temperature for VHF observed in our temperature measurements and calculations is not big as well. Difference in iodine pressure due to difference in sodium loss rate can explain part of the results on tungsten deposition on the arc tube wall but not all. Changes in the electrode structure play a role, too.

Surface structure: From an overview of all the electrode pictures it can be concluded that at high frequency operation the electrodes are less deformed and show less changes of their structure and appearance. Cracks have been observed in the surface of electrodes operated at low frequency as can be seen in figure 5. A mechanism that can explain this crack formation is the so called "thermal ratcheting" [7]. Thermal stresses due to cyclic heating and cooling can cause plastic deformation when the stresses are larger than the yield stress. Under certain conditions the small plastic deformations of each cycle may add up and cause a real deformation of the structure. This could happen during the periodic heating and cooling in the anode and cathode phase.. This causes periodic stresses that can lead to build up of more permanent stresses, eventually leading to structural damage like the cracks shown in the lower left hand picture of figure 5. The calculated temperature fluctuation on CWA is $180 \mathrm{~K}$ (figure 8). On the longer term cracks can lead to breaking up of the tip structure and to more than normal burn back of the electrode. A closer inspection of the lumen maintenance data of individual lamps has revealed that there is sometimes between two successive measuring points a sudden drop in maintenance of more than $10 \%$, followed by a more smooth and normal course of the curve. The name incident was introduced for such an event. It appeared that these incidents start occurring after about 2,500 hours. That such an incident can cause a real sudden drop in maintenance is shown in figure 11. In one of our intensive monitoring tests such a sudden drop in maintenance was caught: within 70 hours the luminous output of the lamp dropped from 83 down to $72 \mathrm{~lm} / \mathrm{W}$. Before and after this 70 hours time interval, the maintenance decrease was much slower. 
Interesting is the observed lamp voltage slump of a few volts during this event.

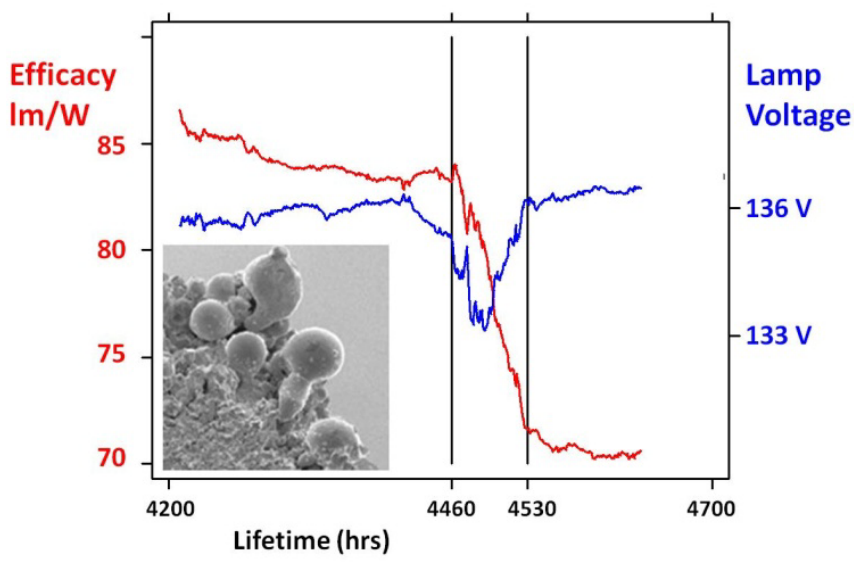

Figure 11. An example of a lamp of which the RMS lamp voltage and lumen per watt output was continuously monitored and that showed a sudden strong drop in lumens per watt that lasted 70 hours.

The minimum in the lamp voltage is most probably caused by a change in cathode-fall due to a change in arc attachment. This leads to the following interpretation. In the cathode phase of the $60 \mathrm{~Hz}$ operation the arc is contracted to a spot. When the arc attaches on a structural element of the electrode tip that has less thermal contact with the rest of the electrode (like one of the protrusions shown in fig. 11) this can lead to strong heating of this element. This results in the observed voltage drop since less input power (and thus less cathode fall) is needed to keep such a small protrusion on thermionic emission temperature. Overheating of the small structural element leads to a strong evaporation, i.e. transfer of tungsten into the gas phase, and to an abnormal strong blackening of the wall. This stops when the structural element has disappeared or when the arc jumps to another spot. These incidents have not been observed for lamps operated at VHF (100 kHz).

An interesting observation is the formation of small protrusions on the upper electrodes during low frequency operation as shown in the upper left picture of figure 5. The observed structures suggest that it is not only erosion and transport away of tungsten but also growth of protrusions. Most probably the flatter part of the tip just erodes by "evaporation" of tungsten, whereas close to the rim of the tip structures grow. This growth can be explained with the same mechanism as used for the deposition of an emitter monolayer on the electrode tip during the cathode phase. During the cathode phase tungsten ions are transported by cataphoresis to the spot where the constricted arc attaches and they deposit there. During the following anode phase with diffuse attachment tungsten is transported away, but now from the whole tip surface of the electrode. So during the cathode phase there is local growth and during the anode phase a non-local removal. This can lead to the formation of a protrusion.

Thermodynamic modeling shows that this is a plausible explanation if the temperature of the hot spot in front of the electrode is about $6000 \mathrm{~K}$ and if it is assumed that $10 \%$ of the current is carried by ions. Then the degree of ionization of tungsten in the gas phase is high enough to enable, within 4000 hours, the growth of a number of protrusions with the size as shown in figure 5. That the protrusions are only found at the upper electrode is then due to the difference in hot spot temperature between the lower electrode and the upper one. Demixing in the arc causes the hot spot temperature to be higher near the upper electrode than in front of the lower one.

\section{Conclusions}

Lumen maintenance results of CWA-operated lamps show that thorium is active as an emitter in this type of sodium scandium lamps.

The good maintenance at high frequency operation implies that thorium is still active as emitter, this despite of the fact that due to the high frequency there will be no field assisted transport of emitter ions (cataphoresis) to the surface in the cathode phase. There is only the normal emitter adsorption but apparently this is sufficient to maintain the thorium atoms on the electrode surface, also in the anode phase. Important here is that thorium atoms are very strongly adsorbing on a tungsten surface. 
Experimental and analytical results indicate that sodium loss is less on VHF. This means that the increase in iodine pressure is less and that thus the transport rate of tungsten from the electrodes to the wall is less, i.e. less blackening of the wall.

The high frequency operation leads to the absence of periodic temperature fluctuations of the electrode tip due to heating and cooling in the cathode and anode phase. This will cause less or no stress build up, less deformation and cracking due to thermal ratcheting. A less damaged tip surface is the result and this explains why no sudden lumen maintenance drops (incidents) have been found with VHF.

\section{References}

[1]Lamouri A, Naruka A and Sules J 2007 Proceedings The 11th International Symposium on the Science \& Technology of Light Sources, May $20^{\text {th }}-24^{\text {th }}$, Shanghai, China, p. 543

[2] Lamouri A, Naruka A, Sulcs J, Varanasi C and Brumleve T 2005 J. Phys. D: Appl. Phys. 38 30283032

[3] van Erk W, Cobben P and Bennema P 1993 Proc. of third Int. Symp. on High Temperature Lamp Chemistry vol 93-16, Proc. Electrochem. Soc. pp 94 - 107

[4] van Erk W, Tu T and Suijker J 2005 J. Phys. D: Appl. Phys. 38 3040-3046

[5] Luijks G, Nijdam S and van Esveld H 2005 J. Phys. D: Appl. Phys. 38 3163-3169

[6] Langenscheidt o, Westermeier M, Reinelt J, Mentel J, Awakowicz P 2008 J. Phys. D: Appl. Phys.

41144005

[7] Parkes E 1964 Thermal Stress, ed P P Benham and R Hoyle (London: Pitman) 